\title{
Effects of fining treatment and storage temperature on the quality of clarified banana juice
}

\begin{abstract}
The clarified banana juice was subjected to different treatment namely bentonite, combination of gelatin and bentonite and control and stored at 4,25 and $37{ }^{\circ} \mathrm{C}$ for 24 weeks. The effects of fining treatment, storage temperature and storage time on turbidity, total polyphenol, browning index, microbiological, and sensory quality of clarified banana juice were evaluated during storage. Fining treatment, storage temperature and storage time had a significant $(\mathrm{p}<0.001)$ effect on turbidity, total polyphenol and browning index of clarified banana juice. Turbidity and browning index of juice were reduced by fining treatment with bentonite and a combination of gelatin and bentonite but increased with storage temperature and storage time. A significant decrease in total polyphenol content and increase in turbidity and browning index were detected for all juice samples during storage. However, it was noted that changes were significantly greater in control juice stored at higher temperature than in juice stored at 4 or $25{ }^{\circ} \mathrm{C}$ for up to 6 months. Sensory evaluation revealed that juices treated with bentonite or a combination of gelatin and bentonite and stored at 4,25 or $37{ }^{\circ} \mathrm{C}$ were acceptable for up to six months, whereas untreated juice stored at $37{ }^{\circ} \mathrm{C}$ was only acceptable for up to 16 weeks.
\end{abstract}

Keyword: Clarified banana juice, Fining agent, Storage temperature, Storage time 